\title{
Retracted COVID-19 articles: a side-effect of the hot race to publication
}

\author{
Parisa Soltani ${ }^{1}$ (D) $\cdot$ Romeo Patini $^{2}$ (D)
}

Received: 26 June 2020 / Published online: 5 August 2020

(c) Akadémiai Kiadó, Budapest, Hungary 2020

\section{Dear Editor:}

In early 2020, coronavirus disease 2019 (COVID-19) caused a pandemic, affecting the entire globe. Initially, the disease was relatively unknown. However, as COVID-19 became more widespread, our knowledge regarding the virus and its resultant disease increased. The healthcare system and policymakers in different countries relied on articles published on the subject, from epidemiological features to useful drugs and at-risk populations, for their decisions. Thousands of research articles have since been published on COVID-19 and severe acute respiratory syndrome coronavirus 2 (SARS-CoV-2). Researchers were and are keen to publish their COVID-19-related research as quickly as possible in this hot race to publication. In this atmosphere, the accuracy and quality of published articles might cause some concerns. Although pre-publication peer-review systems are undeniably robust and traditionally employed in scientific publications, post-publication review is flourishing during this pandemic era. Researchers and scholars have critically scrutinized the COVID19-related scientific output of medical journals, leading to several corrections and retractions. Moreover, some authors later noticed some inconsistencies in their published work, which forced them to withdraw their articles. Through this letter, the authors aimed to show an evaluation of the retracted COVID-19 articles.

The database of retraction watch was searched on June 18, 2020, using "COVID-19", "coronavirus disease 2019", "coronavirus 2019", "SARS-COV-2", and "2019-nCov" as keywords. Additionally, the special webpage in retraction watch was analyzed for retracted or withdrawn articles (Marcus 2020). The search retrieved a total of 26 articles from the retraction watch database. Of these articles, two were temporarily retracted (Cai et al. 2020; Yin 2020), two received an expression of concern (Gautret et al. 2020; Wang et al. 2020a, b), and two have been currently corrected (Sriwijitalai and Wiwanitkit 2020; Tang et al. 2020). One was a withdrawn preprint as it was submitted to the preprint server without the full consent of all the authors. This preprint is now published in the Cell Host and Microbes journal (Chen et al. 2020). Moreover, a reliable access was not obtained to one

Romeo Patini

romeo.patini@unicatt.it

1 Department of Oral and Maxillofacial Radiology, Dental Implants Research Center, Dental Research Institute, School of Dentistry, Isfahan University of Medical Sciences, Isfahan, Iran

2 Department of Head, Neck and Sense Organs, School of Dentistry, Catholic University of Sacred Heart, Rome, Italy 
Fig. 1 Number of retracted/withdrawn COVID-19 articles from different countries
Table 1 Reasons for retraction/ withdrawal of COVID-19 articles

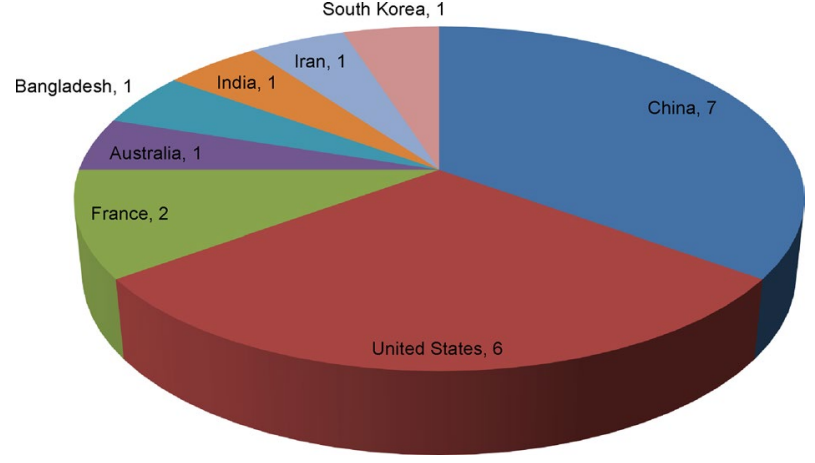

Reason for retraction or withdrawal Number of cases

\begin{tabular}{ll} 
Concerns, issues, or errors in results and/or conclusions & 8 \\
Concerns, issues, or errors in data & 7 \\
Duplication due to error of the journal/publisher & 2 \\
Duplication due to report of the case by another team & 1 \\
Error in analysis & 1 \\
Copyright claims & 1 \\
Ethical violation by the author & 1 \\
Lack of approval from a third party & 1 \\
Concerns/issues about third party involvement & 1 \\
Investigation by a third party & 1 \\
Concerns/issues about authorship (dishonest presentation) & 1 \\
Not mentioned & 2 \\
\hline
\end{tabular}

article titled "Corona Virus Killed by Sound Vibrations Produced by Thali or Ghanti: A Potential Hypothesis" mentioned in the special COVID-19 webpage in retraction watch. Finally, one preprint shown in the retraction watch search was resubmitted without explanation (Daneshkhah et al. 2020). The characteristics of the remaining seventeen articles are discussed below (Pradhan et al. 2020; Yang et al. 2020; Wang et al. 2020a, b; Bae et al. 2020; Parves 2020; Chu et al. 2020; Mehra et al. 2020a, b; Karami et al. 2020; Davido et al. 2020; Nouvier et al. 2020; Gormley and Ngan 2020; Zhuang et al. 2020; Siyu et al. 2020; Zeng and Zhen 2020; Luo et al. 2020; Tofade and Daftary 2020).

Among the seventeen articles involved in this analysis, six were preprints (and thus article type was not assigned), five were research articles, two were letters, two were case reports, and two were sorts of commentaries. The countries with the highest numbers of retracted or withdrawn articles were China with seven articles, followed by the United States with six articles (Fig. 1). Reasons for retraction or withdrawal were searched both in the journal websites and in the retraction watch database. According to this search, the most common reasons for retraction were concerns, issues, and errors in results and/or conclusions, followed by concerns, issues, and errors in data (Table 1).

Some of these retractions even drew the attention of news outlets and have been widely discussed among the public. The most prominent examples are the retraction of 
articles from The Lancet and The New England Journal of Medicine. The Lancet article reported that increased in-hospital mortality was associated with hydroxychloroquine or chloroquine, while The New England Journal of Medicine article did not confirm the association of angiotensin-converting enzyme inhibitors and angiotensin-receptor blockers with in-hospital deaths in COVID-19 patients (Hopkins and Gold 2020; Davey 2020). However, both articles were retracted after a further post-publication review. Another interesting case was a letter submitted to The Lancet Global Health describing the situation of nurses in Wuhan, China, allegedly in a first-person narrative. However, the authors later informed the journal that the experience described in the letter was not a first-hand account. In another incident, the authors of a case report on the first COVID-19-related mortality in pregnant women, withdrew the report when they were notified that another team in a different hospital had submitted and published the same report. In two separate instances, a journal made the mistake of duplicate publication of an article. In general, it seems the main reason underlying these retractions and withdrawals is the rush to quickly publish the COVID-19-related articles, whether by the authors or the journal editors and review teams. The publishing parties must keep in mind that swiftly published but erroneous data is not helpful for the medical community in their ongoing battle with COVID-19. What we actually need (possibly more than any time) is correct, meticulous, and unbiased information passed through rigorous critical appraisal methods of the scientific community.

Acknowledgements We would like to thank Editage (www.editage.com) for English language editing.

Author contributions The authors jointly performed the search and data extraction procedures. PS prepared the original draft and RP critically revised it.

Funding None.

Data availability Available from the authors upon request.

\title{
Compliance with ethical standards
}

\author{
Conflict of interest None.
}

\section{References}

Bae, S., Kim, M.-C., Kim, J. Y., Cha, H.-H., Lim, J. S., Jung, J., et al. (2020). Effectiveness of surgical and cotton masks in blocking SARS-CoV-2: a controlled comparison in 4 patients. Annals of Internal Medicine. https://doi.org/10.7326/M20-1342.

Cai, Q., Yang, M., Liu, D., Chen, J., Shu, D., Xia, J., et al. (2020). Experimental treatment with favipiravir for COVID-19: an open-label control study. Engineering. https://doi.org/10.1016/j.eng.2020.03.007.

Chen, Z., Zhang, W., Lu, Y., Guo, C., Guo, Z., Liao, C., et al. (2020). From SARS-CoV to Wuhan 2019-nCoV outbreak: Similarity of early epidemic and prediction of future trends. Cell Host Microbes. https://doi. org/10.1101/2020.01.24.919241.

Chu, P., Zhou, Z., Gao, Z., Cai, R., Wu, S., Sun, Z., et al. (2020). Computational analysis suggests putative intermediate animal hosts of the SARS-CoV-2. BioRxiv. https://doi.org/10.1101/2020.04.04.025080.

Daneshkhah, A., Eshein, A., Subramanian, H., Roy, H. K., \& Backman, V. (2020). The role of vitamin D in suppressing cytokine storm in COVID-19 patients and associated mortality. MedRxiv.

Davey, M. (2020). Covid-19 studies based on flawed Surgisphere data force medical journals to review processes. The Guardian.

Davido, B., Lansaman, T., Lawrence, C., Alvarez, J.-C., Bouchand, F., Moine, P., et al. (2020). Hydroxychloroquine plus azithromycin: a potential interest in reducing in-hospital morbidity due to COVID-19 pneumonia (HI-ZY-COVID)? MedRxiv. https://doi.org/10.1101/2020.05.05.20088757. 
Gautret, P., Lagier, J.-C., Parola, P., Meddeb, L., Mailhe, M., Doudier, B., et al. (2020). Hydroxychloroquine and azithromycin as a treatment of COVID-19: results of an open-label non-randomized clinical trial. International Journal of Antimicrobial Agents. https://doi.org/10.1016/j.ijantimicag.2020.105949.

Gormley, A., \& Ngan, K. (2020). WITHDRAWN: COVID-19 emergency responders in FDA's center for drug evaluation and research. Journal of the American Pharmacists Association. https://doi.org/10.1016/j. japh.2020.04.007.

Hopkins, J. S., \& Gold, R. (2020). The big-data mystery behind retracted Covid-19 studies of hydroxychloroquine, other drugs. The Wall Street Journal.

Karami, P., Naghavi, M., Feyzi, A., Aghamohammadi, M., Novin, M. S., Mobaien, A., et al. (2020). Mortality of a pregnant patient diagnosed with COVID-19: A case report with clinical, radiological, and histopathological findings. Travel Medicine and Infectious Disease. https://doi.org/10.1016/j.tmaid.2020.101665.

Luo, X., Hai, Z., Xiao, S., Yang , H., Jing, X., \& Wang, H., et al. (2020). An epidemiological investigation of 2019 novel coronavirus diseases through aerosol-borne transmission by public transport. Practical Preventive Medicine, 1-3.

Marcus, A. (2020). Retracted coronavirus (COVID-19) papers. https://retractionwatch.com/retracted-coronaviru S-covid-19-papers/. Accessed June 18, 2020.

Mehra, M. R., Desai, S. S., Kuy, S., Henry, T. D., \& Patel, A. N. (2020a). Cardiovascular disease, drug therapy, and mortality in COVID-19. New England Journal of Medicine. https://doi.org/10.1056/NEJMc2021225.

Mehra, M. R., Desai, S. S., Ruschitzka, F., \& Patel, A. N. (2020b). Hydroxychloroquine or chloroquine with or without a macrolide for treatment of COVID-19: a multinational registry analysis. The Lancet. https://doi. org/10.1016/S0140-6736(20)31180-6.

Nouvier, M., Chalençon, E., Novel-Catin, E., Pelletier, S., Hallonet, P., Charre, C., et al. (2020). First viral replication of Covid-19 identified in the peritoneal dialysis fluid of a symptomatic patient. Bulletin de la Dialyse a Domicile, 3(1), 49-50. https://doi.org/10.25796/bdd.v3i1.54503.

Parves, R. (2020). Analysis of Ten Microsecond simulation data of SARS-CoV-2 dimeric main protease. BioRxiv. https://doi.org/10.1101/2020.04.10.036020.

Pradhan, P., Pandey, A. K., Mishra, A., Gupta, P., Tripathi, P. K., Menon, M. B., et al. (2020). Uncanny similarity of unique inserts in the 2019-nCoV spike protein to HIV-1 gp120 and Gag. BioRxiv. https://doi. org/10.1101/2020.01.30.927871.

Siyu, C., Xia, M., Wen, W., Cui, L., Yang, W., Liu, S., et al. (2020). Mental health status and coping strategy of medical workers in China during The COVID-19 outbreak. MedRxiv. https://doi. org/10.1101/2020.02.23.20026872.

Sriwijitalai, W., \& Wiwanitkit, V. (2020). Corrigendum to "COVID-19 in forensic medicine unit personnel: Observation from Thailand" [J Forensic Legal Med 72 May 2020, 101964]. Journal of Forensic and Legal Medicine, 72, 101967. https://doi.org/10.1016/j.jflm.2020.101967.

Tang, X., Wu, C., Li, X., Song, Y., Yao, X., Wu, X., et al. (2020). On the origin and continuing evolution of SARS-CoV-2. National Science Review. https://doi.org/10.1093/nsr/nwaa036.

Tofade, T., \& Daftary, M. (2020). WITHDRAWN: Managing college operations during the coronavirus outbreak. Journal of the American Pharmacists Association. https://doi.org/10.1016/j.japh.2020.04.004.

Wang, X., Xu, W., Hu, G., Xia, S., Sun, Z., Liu, Z., et al. (2020a). SARS-CoV-2 infects T lymphocytes through its spike protein-mediated membrane fusion. Cellular and Molecular Immunology. https://doi. org/10.1038/s41423-020-0424-9.

Wang, X., Yuan, J., Zheng, Y., Chen, J., Bao, Y., Wang, Y., et al. (2020b). Retracted: Clinical and epidemiological characteristics of 34 children with 2019 novel coronavirus infection in Shenzhen. Chinese Journal of Pediatrics. https://doi.org/10.3760/cma.j.issn.0578-1310.2020.0008.

Yang, Y., Lu, Q., Liu, M., Wang, Y., Zhang, A., Jalali, N., et al. (2020). Epidemiological and clinical features of the 2019 novel coronavirus outbreak in China. MedRxiv. https://doi.org/10.1101/2020.02.10.20021675.

Yin, Z. (2020). COVID-19: Should sexual practices be discouraged during the pandemic? Journal of the American Academy of Dermatology. https://doi.org/10.1016/j.jaad.2020.04.140.

Zeng, Y., \& Zhen, Y. (2020). RETRACTED: Chinese medical staff request international medical assistance in fighting against COVID-19. The Lancet Global health. https://doi.org/10.1016/S2214-109X(20)30065-6.

Zhuang, G., Shen, M., Zeng, L., Mi, B., Chen, F., Liu, W., et al. (2020). WITHDRAWN: Potential false-positive rate among the' asymptomatic infected individuals' in close contacts of COVID-19 patients. Zhonghua liu xing bing xue za zhi, 41(4), 485-488. https://doi.org/10.3760/cma.j.cn112338-20200221-00144. 